\title{
Rewards from public office and selection of politicians by parties*
}

\author{
Fabio Cerina $^{\dagger} \quad$ Luca G. Deidda ${ }^{\ddagger}$ \\ This version: September 2016
}

\begin{abstract}
We investigate the relationship between quality of politicians, defined in terms of their competence (skills), and rewards from public office in a game between parties and citizens in which parties play a crucial role in the selection of politicians. Parties shape the selection of politicians by manipulating information about the quality of their candidates. An increase in the rewards from public offices leads to two opposing effects on the average quality of politicians. First, a selection effect, whereby more skilled citizens enter politics, leading to an increase in average quality. Second, a manipulation effect, as parties have the incentive to further manipulate information so to increase the probability of election for their unskilled candidates from whom they can extract higher rents in the form of service duties. We find that the second effect dominates when: i. Parties' costs of manipulating information are sufficiently low; ii. Even in the absence of manipulation, the quality of information available to citizen about candidates is sufficiently poor; iii. Net gains from becoming a politicians for unskilled citizens are sufficiently larger than those for skilled citizens. These findings provide a rationale for the ambiguous sign of the empirical relationship between quality and pay of politicians.
\end{abstract}

JEL Classification: D72, H70, J33.

Keywords: Selection, Public office rewards, Political parties, Quality of politicians, Information manipulation.

* We thank Augustin Casas, Dong Hee Joe, Raquel Fernandez, Johnatan Klick, Miguel Ledesma, Francesco Lippi, Bryan McCannon, Naci Mocan, Massimo Morelli, Alessio Moro, Andrea Moro, Paolo Roberti and Giovanni Sulis for insightful conversations and suggestions, Michele Argiolas for excellent research assistance, and participants at seminars at the University of Sassari and University of Pamplona and conferences at Aix-en-Provence (ASSET 2014 and LAGV 2015), Alghero (IIBEO 2015), Luxembourg (PET 2015). Luca Deidda gratefully acknowledges financial support by the Italian Ministero dell'Universit (PRIN), and Fondazione Banco di Sardegna.

†E-mail: fcerina@unica.it. Address: Università di Cagliari, Dipartimento di Scienze Economiche ed Aziendali and CRENoS, Viale Fra Ignazio 78, 09123 - Cagliari (Italy).

${ }^{\ddagger}$ Corresponding author. Email: deidda@uniss.it. Address: Università di Sassari, DISEA and CRENoS, Via Muroni 21, 07100, Sassari (Italy). 


\section{Introduction}

The tradition view in political economy has been for a long time that good politics and good policy are the result of well-designed institutional incentives (see Besley, 2005, for a general discussion). More recently, in the literature there has been a growing attention to the notion that - aside from incentives - intrinsic qualities of politicians such as honesty and competence could well matter for quality policies and quality government, which could have a significant impact on socio-economic outcomes ${ }^{1}$. If so, the role of institutions, including political parties, in selecting politicians becomes crucial.

The focus of the present paper is on the relationship between politicians' quality, defined in terms of competence, i.e. skills, and rewards from public officer. In particular, in a model in which parties play a role in the selection of politicians, we ask whether raising the pay of politicians leads necessarily to politicians of higher quality. As figure 1 and 2 show, prima facie evidence about trends in the pay of Italian Members of Parliament (MPs) and US Members of Congress (MCs) and their education attainments - a measure of skills widely used in the empirical literature - suggests that paying politicians more is not necessarily associated with higher quality. ${ }^{2}$

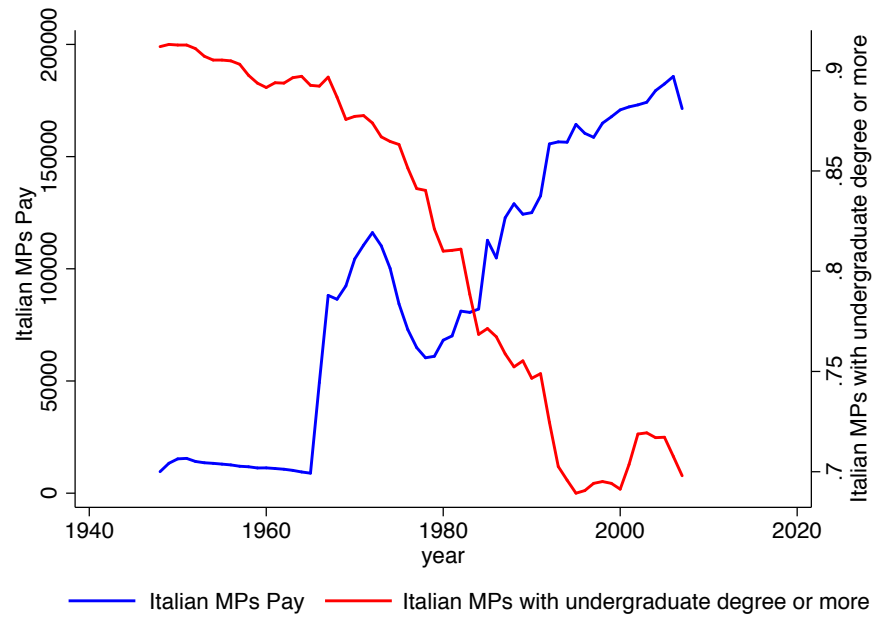

Figure 1: MPs reward in real terms (2005 dollars) and percentage of MPs with undergraduate degree in Italy 19482007. Source: Fondazione De Benedetti (FRDB), "Italian Members of the Parliament" dataset. Data originally collected by Merlo et al, 2008, with support of FRDB.

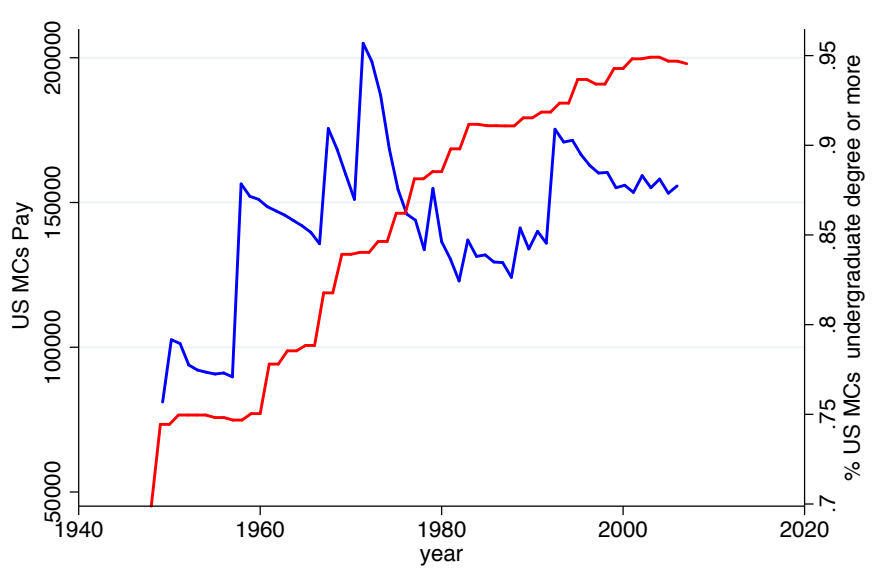

_ US MCs Pay _ — — US MCs with undergraduate degree or more

Figure 2: MCs reward in real terms (2005 dollars) and percentage of MCs with undergraduate degree in US 19482007. Source: Online bibliographical directory of the United States Congress.

While in the US the percentage of MCs with undergraduate education or more increases with pay, this is not the case in Italy, where the two phenomena are strongly negatively correlated. ${ }^{3} \mathrm{~A}$ recent strand of empirical literature addresses the challenging task of identifying the causal effect that politicians' pay could have on quality of politicians. Using data from local Italian municipalities, Gagliarducci and Nannicini, 2013, show that a higher wage attracts more-educated candidates and that

\footnotetext{
${ }^{1}$ See Besley, 2005, Besley et al., 2013, and Besley et al., 2005.

${ }^{2}$ Education attainments are a commonly used proxy for competence/skills in the political economy literature. Notable examples include see Besley, 2004, Ferraz and Finan, 2009, Fisman et al., 2015, Gagliarducci and Nannicini, 2013.

${ }^{3}$ Correlation between politicians' pay and education is around $31 \%$ in the US and $-91 \%$ in Italy.
} 
better-paid politicians size down the government machinery by improving efficiency. ${ }^{4}$ Similarly, using municipalities data from Mexico, Dal Bo, Finan and Rossi, 2013, find that announcing a higher salary results in smarter applicants, with better personality traits, higher earnings and a better occupational profile. Finally, Ferraz and Finan, 2009, find that in the case of Brazilian municipalities, higher wages result in more educated candidates.

These findings support the case for positive causal relationship between pay of politicians and quality of politicians, at local level. However, things change considerably when national politics is considered. Using data on Members of the European Parliament (MEPs), Fisman et al., 2015, find that 'high salaries reduce the quality of elected MEPs (as proxied by the quality of the colleges they attended)", (page 3). Relatedly, Braendle, 2015, finds no significant impact of MEPs' pay on MEPs' quality as proxied by formal education, occupational background and political experience. Kotakorpi and Poutvaara, 2011, study the relationship between politicians' wage and quality in Finnish National Parliament. They report that the wage increase led to more educated female candidates but had no effect on the composition of male candidates. Finally, Hoffman and Lyons, 2013, find almost no correlation between salary and politician performance or quality of US governors and state legislators.

We propose a theory about the role of parties in the selection of politicians that helps explaining why the sign of the relationship between pay and quality of politicians is ambiguous and it is more likely to be positive at local level than at national level. We model parties' role in determining quality of politicians in a setup related to the theory of quality of elected officials put forward by Caselli and Morelli, 2004. In the model, citizens who wish to be elected politicians have to become party members, first. If elected, they contribute service duties to their party. ${ }^{5}$ Citizens are of two types (i.e. qualities): skilled and unskilled. Unskilled politicians lead to a more costly scheme for the provision of the essential public good compared to skilled ones. Moreover, skilled individuals earn a higher salary than unskilled ones if working in the private sector. Ex ante, individual type is private information. However, citizens observe a public informative signal about candidates' individual type. Parties, which observe the type of each of their members at no cost, shape the selection of politicians by engaging in costly manipulation of information which reduces the informativeness of the public signal about the quality of their candidates. Citizens and parties play the following game. Parties enter the political arena and citizens decide whether to become members of one of them. Then, parties decide the degree of information manipulation about candidates and the rents to be extracted from elected politicians in the form of service duties, while party members decide whether to stay in politics or quit. Then, elections take place, citizens vote, and payoffs are realized.

We show that increasing politicians pay might actually worsen the average quality of politicians so long as, (i) Parties face low costs of manipulating information about the quality of candidates (captured society), and/or (ii) even in the absence of manipulation citizens would be poorly informed (unaware society), and/or (iii) Net gains from becoming a politicians for unskilled citizens is sufficiently larger than that for skilled citizens.

The intuition behind our main result is as follows. Unskilled citizens have a lower opportunity

\footnotetext{
${ }^{4}$ According to their findings, most of this effect can be attributed to the selection of competent politicians.

${ }^{5}$ These duties can be interpreted both as monetary transfers as well as transfers in kinds.
} 
cost of entering politics than skilled ones, given that they earn less in the private sector. Accordingly, unskilled citizens engaging in politics are more subject to rent extraction under the form of service duties by their party than skilled ones. Because of that, parties might favour the election of unskilled politicians. Under this scenario, increasing the pay of politicians has two opposing effects. On the one hand, it might favour the entry of skilled citizens into politics. Other things equal, this positive selection effect would increase quality of elected politicians. On the other hand, entry of skilled citizens into politics worsens election prospects for unskilled party members, who would be therefore less willing to contribute service duties to the party if elected. To counteract that effect, parties manipulate information more (manipulation effect) so to reduce the informativeness of the public signal about candidates' type, in order to improve unskilled members' chances to be elected. Such increase in information manipulation might undo the positive selection effect, thereby resulting in a negative relationship between pay and quality of politicians.

According to our result, if quality of politicians and politicians' pay are negatively correlated in the case of Italy, and positively correlated in the case of the US - other things equal - we should expect the cost of manipulating information and/or the level of citizen awareness to be lower in Italy than in the US. Finding proper proxies for these variables is not an easy task. Having said that, if one accepts the idea that parties' manipulation technology is more effective, and citizens' awareness is lower in countries where, (i) press is not entirely free and independent, and (ii) citizens are less informed about political and social issues, respectively, then we could refer to some official measures of these two phenomena, and see how they compare in the two countries. Two important and independent watchdog organizations, Reporters without Borders and Freedom of the House, provide two indexes of freedom of press according to which they rank countries from 2002 up to 2015. According to both indexes, Italian press lags significantly behind that of the US in terms of freedom. As for citizens' awareness, according to the Index of Ignorance elaborated by Ipsos MORI which "highlights how wrong the public across 14 countries are about the basic make-up of their populations and the scale of key social issues" (taken from Ipsos-MORI website), Italy is the more ignorant country among the 14 being considered. ${ }^{6}$ The behavior of these proxies of the cost of information manipulation across countries are entirely in agreement with the model. Freedom of press and society awareness are respectively higher and lower in US compared to Italy, as our theory would predict.

Finally, our model also offers an explanation of the fact that the relationship between quality and pay of politicians is generally positive only at local municipality level, might be due to the fact that informational asymmetries, and therefore citizens' awareness, are more of an issue at national level, where it is less likely that citizens have a direct knowledge of the candidates.

The rest of the paper is as follows. Section 2 locates our contribution within the related literature. Section 3 presents the model. Section 4 describes payoffs and actions. Section 5 develops the equilibrium analysis. Section 6 presents the main result about quality and pay of politicians. Section 7 concludes the paper.

\footnotetext{
${ }^{6}$ The 14 countries are Australia, Belgium, Canada, France, Germany, Hungary, Italy, Japan, Poland, South Korea, Spain, Sweden, Great Britain and the United States of America.
} 


\section{Related Literature}

We propose a model that delivers an ambiguous relationship between pay and quality of politicians, based on the idea that parties might not have the incentive to select the best politicians. Therefore, our paper relates directly to two strands of literature: the one on selection of politicians by parties, and that on the relationship between rewards from politics and quality of politicians.

The main motivation behind the literature on "political selection" - surveyed by Besley, 2005, is that there is a general concern about the quality of elected politicians. Crucially, "(c)andidates are typically chosen by political parties. This fact raises the question of why a party would ever put a bad candidate up for election", (Besley 2005, page 55). Mattozzi and Merlo, 2015, develop a model in which a "mediocracy" equilibrium obtains, characterized by low quality politicians. As they explain, such equilibrium is the outcome of following trade-off: "On the one hand, recruiting the best possible individuals may enhance the party's electoral prospects in a competitive electoral environment (competition effect). On the other hand, recruiting a relatively "mediocre" but homogeneous group of individuals may maximize their collective effort on behalf of the party since the presence of "superstars" may discourage other party members and induce them to shirk (discouragement effect)" (page 32). Carrillo and Mariotti, 2001, emphasize the discrepancy between parties' and voters' objectives. In their model, contrary to parties, voters would like to always replace mediocre incumbents. Even under symmetric information, their model shows that electoral competition may lead parties not to select the most suitable candidates. Finally, Besley et al., 2014, propose another mechanism through which parties might not be willing to select the most competent candidates. In their model "a male party leader may feel threatened by appointing women and competent men, especially when he is of mediocre competence. This creates a dilemma for party leaders who may only be able to appeal to voters by risking their own position" (page 3). They show how a mediocre male leader responds to this concern by appointing fewer women and competent men.

The papers discussed above develop intuitions about parties' incentives to (not) select best politicians that are different from the one we focus on. Yet, their results point in the same direction as ours: bad politicians could be in office also because parties might have insufficient incentives to select the good ones. Closer to our intuition as to why this might happen, Besley, 2005, page 55, suggests that "if rents are earned by parties as well as successful candidates, and protection of those rents is dependent on selecting bad politicians with little public service motivation, then the party may have an interest in putting up bad candidates".

As far as the relationship between pay and quality of politicians is concerned, Caselli and Morelli, 2004, predict that increasing politicians' pay always increases politicians' quality due to a selection effect. We significantly depart from their setup by introducing parties and endogenizing the information that citizens have about candidates. Our results show that the selection effect dominates - so that a positive relationship between quality and pay of politicians emerges - if and only if parties face sufficiently high costs of manipulating information and/or, in the absence of information manipulation, the society is sufficiently informed.

Using a different setup, Mattozzi and Merlo, 2008, show that increasing the pay for public service 
makes politics more attractive at all skill levels, which reduces quality, but also makes more attractive for skilled politicians to stay in politics longer. As a result, the impact of pay for public office on quality is ambiguous. In our setup, a similar intuition applies that a higher pay makes politics a more attractive option for both unskilled and skilled agents. Yet, in our case, the ambiguous relationship between pay and quality of politicians is due to parties' incentives to manipulate information about candidates, rather than to opportunity cost considerations by skilled politicians.

Messner and Polborn, 2004, also show that quality of politicians might go down following an increase in politicians' wage. Their result, though, stems from an intuition very different from ours. In their setup, citizen care about quality of politicians, and, crucially, each citizen knows he can affect the quality of politicians if entering politics. Hence, while other things equal an increase in salary makes politics more attractive for a skilled citizen, it also increases the incentive of each skilled citizen not to run for election and free ride on other skilled citizens instead, counting on the fact that some of them will run.

While all the above mentioned contributions abstract from parties, Poutvaara and Takalo, 2007, integrate political parties into a citizen-candidate model and show that the effects of pay for politicians on candidate quality may be non-monotonic. Their setup significantly differs from ours in several aspects: the number of political parties is fixed, parties have no role in manipulating information, while candidate ability affects both outside options and the probability of sending a good signal in costly campaigning.

We conclude the discussion of the related literature with two observations about (i) the informative role of parties and (ii) the notion of quality of politicians in our paper. First, in our model, parties shape the quality of politicians also by affecting the public signal about the quality of candidates through information manipulation. This relates our paper to the literature on the informative role of parties. The idea that parties possess more information than voters about candidates' quality has wide recognition in the literature (Calliaud and Tirole, 2002, Snyder and Ting, 2002). The issue of whether they have the right incentives to disclose such information truthfully has also received some attention. For instance, Galeotti and Mattozzi, 2011, build a model according to which "in richer communication networks parties disclose less political information and voters are more likely to possess erroneous beliefs about the characteristics of the candidates running for office" (page 307). Moreover, some influential papers on media capture have given a prominent role to parties (Djankov et al., 2003) and more generally to the government (Besley and Prat, 2004) in capturing media in order to affect the political outcomes, which is consistent with the intuition we develop in our model according to which parties might try to manipulate information rather than disclose it truthfully.

Second, various contributions on quality of politicians, including Bernheim and Kartik, 2014, Besley, 2004, and Caselli and Morelli, 2001, focus on aspects of candidates' type other than competence, such as honesty or public spirit. In that respect, our model could be reinterpreted replacing skilled and unskilled citizens with honest and dishonest ones, with no change in the main result so long as dishonest citizens have more incentives to enter politics than honest ones. As suggested by Caselli and Morelli, 2001, such assumption seems realistic if the governance in public sector is worse than in the private sector, so that it is easier to expropriate cash flows from taxpayers than from private 
enterprises' stakeholders. Under this alternative setting, our theory would contribute to the above mentioned literature by highlighting the possible ambiguous relationship between honesty and pay of politicians, whereby the level of honesty in politics is positively (negatively) related to politicians' pay depending on whether the level of society awareness is high (low) and/or parties ability to manipulate information is low (high).

\section{The model}

Building on Caselli and Morelli, 2004, we develop a game between parties and citizens, in which parties have a key role in the selection of politicians through the manipulation of information about candidates, as fully explained later on in the discussion. The model setup is as follows.

\subsection{Citizens, Party members, Candidates, Politicians and Parties}

The economy is populated by a measure $1+p$ of risk-neutral citizens and an endogenous measure $N$ of political parties. Citizens are of two types: a fraction $s$ is skilled $(s)$ and a fraction $1-s$ is unskilled $(u)$. A citizen of type $i=s, u$, earns $w_{i}$ in the private sector, with $w_{s}>w_{u}$ and, without loss of generality, $w_{u}=1$.

Citizens consume an indispensable public good, whereby citizen's utility would equal zero if the good were not provided. The provision of the public good requires a measure $p$ of citizens being elected to public office, where we call politicians the elected public officials. Politics is run by parties. A citizen can engage in politics and potentially become a candidate who runs for elections only by enrolling as member in a party, first. Participating to politics as a party member entails a participation $\operatorname{cost} \phi$, which measures the direct utility loss that a citizen incurs if engaging in political activity. ${ }^{7}$

Furthermore, we assume that party members face an infinite cost of switching party. ${ }^{8}$ Once endowed with a public informative signal about their type, party members become candidates and run for election.

Politicians are elected among candidates by citizens who vote individually. Each politician is assigned to a public office and receives a monetary reward, $\pi>w_{s}$. Parties operate thanks to the contributions of their politicians, whereby a politician of type $i$ pays service duties $e_{i}$ to the party she belongs to.

Crucially, skilled politicians are assumed to be more productive than unskilled ones: the percapita tax, $t(q)$, necessary to finance the provision of the public good, is decreasing in the quality of politicians, $q$, where $q$ is defined as the fraction of politicians of type $s$.

Following Caselli and Morelli, 2004, in order to eliminate a trivial equilibrium were the entire population runs for office, we assume that there is a measure $v \in[p, 1]$ of citizens who foce an infinite (subjective) cost as party members, so that, $\mu \equiv 1+p-v$ is the measure of citizens who can potentially become politicians.

\footnotetext{
${ }^{7}$ It could be associated with the time that the citizen allocates to this activity at the expenses of other uses.

${ }^{8}$ To be precise, in order for our results to go through we do not need the cost to be infinite, but just sufficiently high that switching party is never an option for party members.
} 


\subsection{The role of Parties}

Since citizen can become candidates only if they are party members, parties play a role as gatekeepers. Moreover, as we explain below, they have a key role in the selection of politicians by shaping the information publicly available about candidates. The information structure is the following. Citizen's type $i$ is private information. However, parties learn the true type of their members, at no cost. Party members become candidates once exposed to an information gathering process (which we do not model explicitly) resulting from the activity of various institutions at society level, including all media for instance, which results in a public signal $j=s, u$ about the type of each member of each party $k$. Let $f(i \mid j)$ the probability that for a party member of true type $i$, the public signal generated is $j$. The structure of the public signal is as follows,

Definition 1 (Signal's structure). For a member of party $k$ of type $i$ the public signal about her type is correct $(i=j)$ with probability $f(i \mid i) \equiv \sigma_{k}$ and incorrect $(i \neq j)$ with probability $f(i \mid j \neq i) \equiv 1-\sigma_{k}$.

Clearly, the signal is informative if and only if $\sigma \geq 0.5$. Each party $k$ has the ability to interfere with the informative process that goes on at society level by engaging in costly manipulation of information about its members. We model this by assuming that each party determines the informativeness of the public signal about its candidates, as measured by $\sigma_{k}$, at a fixed $\operatorname{cost} c\left(\sigma_{k}\right)$. More specifically, we assume that if party $k$ does not interfere, then the public signal signal $j$ for each of its members will be correct with probability $\bar{\sigma}>0.5$. Note that in this case, the party does not incur any cost, i.e. $c(\bar{\sigma})=0$. Alternatively, if the party interferes by manipulating information, this would result in a public signal $j$ that is correct with probability $\sigma_{k}<\bar{\sigma}$ for each of its members, where $\sigma_{k}$ is induced a cost, $c\left(\sigma_{k}\right)>0$, incurred by the party, which is decreasing in $\sigma$, i.e. $c^{\prime}\left(\sigma_{k}\right)<0$. We further assume that manipulating information is increasingly costly, i.e. $c^{\prime \prime}\left(\sigma_{k}\right)>0$. All parties face the same cost $c\left(\sigma_{k}\right)$ of manipulating information. More specifically, for party $k$, the cost of manipulating information is as follows

$$
c= \begin{cases}c\left(\sigma_{k}\right) & \text { if } \sigma_{k}<\bar{\sigma} \\ 0 & \text { if } \sigma_{k}=\bar{\sigma}\end{cases}
$$

Parties' ability to manipulate is low (high) if, for given $\sigma, c(\sigma)$ is high (low) and (in)elastic. In order to avoid trivial results, we assume that for either type and for any feasible set of $\sigma_{k}$, with $k \in N$, the measure of candidates with correct signal is greater than the measure of public offices to be filled. ${ }^{9}$ From now on we refer to $\sigma_{k}$ as the quality of information available about members of party $k$.

According to our assumptions, in the absence of interference by parties, the effectiveness of the process of production of reliable information about candidates at society level is maximum, which results in a public signal of quality $\bar{\sigma}$ about candidate's skills. In other words, $\bar{\sigma}$ measures the quality of information that citizens receive in the absence of information manipulation by parties. Accordingly, we interpret $\bar{\sigma}$ as a measure of the potential maximum quality of information in the society which - other things equal - can be associated with the effectiveness of the institutions involved with the

\footnotetext{
${ }^{9}$ Restricting attention to $\sigma_{k} \geq 0.5$ for all $k \in N$, the necessary and sufficient parameter-restrictions for this to happens are $\mu s>2 p$ and $\mu(1-s)>2 p$. The equilibrium analysis conducted in the paper takes such restrictions into account.
} 
production of information, including media, and/or the degree of citizens' concern about politics. We define aware (unaware) a society is characterized by a relatively high (low) level of $\bar{\sigma}$. In a similar way, parties' ability to manipulate information should be relatively low (high) if they have little control (full control) over the institutions involved with the process of production of information about candidates at society level. Accordingly, we define captured (free) a society in which parties' ability to manipulate information is high (low).

\subsection{Voting Rules}

Voting rules are set in a standard way as follows. Citizen can vote at most one candidate, and votes to non-candidates are void. For a given measure of public offices $x$ to be filled, the measure $x$ of candidates who receive the most votes are elected to office. When necessary, ties are broken with a random draw.

\subsection{Citizen-Parties game.}

The timing of the game played by citizens and parties is as follows.

1. Nature decides individual types;

2. Parties enter;

3. Citizens decide whether to become party members and of which party;

4. Parties set service duties to be contributed by politicians and engage in information manipulation (if any) about their party members, while party members decide to stay and engage in political activity (incurring the cost $\phi$ ) or quit politics (thereby not incurring the participation cost $\phi) ;{ }^{10}$

5. Public signals about the individual type of party members engaged in politics are realized. Party members endowed with such signal become candidates, and citizens vote;

6. The outcome of the game is realized and payoffs are assigned.

\section{Payoffs and actions}

In this section, we analyze parties and citizens' payoffs and actions.

\subsection{Citizens}

Let $d_{i}=\{0,1\}$, the decision to engage in politics or not for a citizen of type $i$ where $d_{i}=1$ in case a citizen decides to start a political career by becoming a party member and engaging in politics, and $d_{i}=0$ otherwise, i.e. if the citizen either does not become a party member or, having become a party member, quits rather than engaging in politics (see stage 4 of the game). A party member

\footnotetext{
${ }^{10}$ Note that costs of switching party are infinite for party members, so switching party is not considered an option.
} 
who engages in politics incurs a cost, $\phi$. Subsequently, once endowed with a public signal $j=s, u$ about her type, party members who engaged in politics become candidates (stage 5 of the game). If elected, as a politician the citizen will receive a payment $\pi$ and will contribute service duties to the party. Let $\alpha^{j}$ be the probability of a candidate to be elected - conditional on a signal $j=s, u$. Then, given the above and considering the probabilistic structure of the signal $j$ provided by definition 1 and related discussion, for a citizen of type $i$, the expected payoff from choosing a political career in party $k$, where such party charges service duties $e_{s, k}$ to skilled politicians and $e_{u, k}$ to unskilled ones, is the following

$$
\begin{aligned}
\left.v_{i}\right|_{d_{i}=1} \equiv & {\left[\alpha^{s} f(s \mid i)+\alpha^{u}(1-f(s \mid i))\right]\left(\pi-e_{i, k}\right)+} \\
& {\left[\left(1-\alpha^{s}\right) f(s \mid i)+\left(1-\alpha^{u}\right)(1-f(s \mid i))\right] w_{i}-\phi-t(q) }
\end{aligned}
$$

Similarly, the payoff of a citizen of type $i$ who does not engage in politics would be

$$
\left.v_{i}\right|_{d_{i}=0} \equiv w_{i}-t(q)
$$

Given the measure $C$ of candidates, each citizen of type $i$ expresses a vote $b_{i} \in \mathbb{R}$. The vote is void if $b_{i} \notin \mathcal{C}$, where $\mathcal{C}$ is the set of candidates, with measure $C$. An action for citizen of type $i$ is a pair $\left(d_{i}, b_{i}\right)$.

\subsection{Parties}

We define $A_{k, s}$, and $A_{k, u}$, with $A_{k, s}, A_{k, u} \in \mathbb{R}$, the measures of members of types $s$ and $u$, respectively, recruited by party, $k$. Accordingly, $A_{s} \equiv \int_{k} A_{k, s}$, and $A_{u} \equiv \int_{k} A_{k, u}$, are the aggregate measures of party members of type $s$ and $u$, respectively, while $A \equiv A_{s}+A_{u}$ is the aggregate measure of party members, independent of type. Note that the following inequalities must hold

$$
\begin{aligned}
& A_{s} \leq \mu s \\
& A_{u} \leq \mu(1-s)
\end{aligned}
$$

as the measure of party members cannot be - conditional on type - larger then the measure of the citizens who can engage in politics.

Given the above, the expected payoff of party $k$ can be written as

$$
v_{k}=e_{s, k}\left(\alpha^{s} \sigma_{k}+\alpha^{u}\left(1-\sigma_{k}\right)\right) A_{k, s}+e_{u, k}\left(\alpha^{s}\left(1-\sigma_{k}\right)+\alpha^{u} \sigma_{k}\right) A_{k, u}-c\left(\sigma_{k}\right)
$$

Each party $k$ chooses whether to enter $r_{k}=1$, not, $r_{k}=0$, the level of informativeness of the public signal about her members (through information manipulation), $\sigma_{k} \in[0, \bar{\sigma}]$, and service duties $e_{u, k}, e_{s, k} \in \mathbb{R}$ to be paid by its unskilled and skilled elected politicians. An action for the party $k$ is a quadruple $\left(r_{k}, \sigma_{k}, e_{s, k}, e_{u, k}\right)$.

\section{$5 \quad$ Equilibrium analysis}

A strategy for a citizen of type $i$ is a probability function $a_{i}$ that maps actions $\left(d_{i}, b_{i}\right)$ on $[0,1]$. A strategy for a party $k$ is a probability function $a_{k}$ that maps actions, $\left(r_{k}, \sigma_{k}, e_{u, k}, e_{s, k}\right)$, to $[0,1]$. Given these definitions, 
Definition 2. An equilibrium is a strategy profile for the citizens and the parties such that each agent's strategy is best reply at any given stage of the game.

Let $C_{k, i}^{j}$ be the measure of candidates of type $i$ and signal $j$ belonging to party $k$, so that, (i) $C_{i}^{j} \equiv \int_{k} C_{k, i}^{j}$ is the aggregate measure of candidates of type $i$ and signal $j$ across parties; (ii) and $C^{j} \equiv C_{s}^{j}+C_{u}^{j}$ is the aggregate measure of candidates of signal $j$ across candidate's types; (iii) $C \equiv C^{s}+C^{u}=C_{u}+C_{s}$ is the total measure of candidates. Note that, $\int_{j} C_{k, i}^{j}=C_{k, i}=A_{k, i}$ as well as $C=A$ as, for any $i=s, u$, and for every party $k$, since all party members become candidates once endowed with the informative signal $j$ produced by their party. Rather than characterizing all equilibria, we restrict our attention to a subset of the possible equilibria that satisfy the following properties:

1. Symmetry. Members, candidates and politicians, are equally divided among parties. That is, for each $k \in N$,

$$
\begin{aligned}
& A_{k, i}=\frac{A_{i}}{N} \\
& C_{k, i}^{j}=\frac{C_{i}^{j}}{N}
\end{aligned}
$$

with $i, j=s, u$;

2. Candidates who have a positive probability to be elected are perceived to be skilled, i.e. they have a high signal, $j=s$. Since voters prefer to vote high-signal candidates than low-signal ones, this condition is equivalent to imposing that there are enough candidates of high signal to cover all seats, i.e.,

$$
C^{s}>p
$$

3. Skill composition of party members: Reluctancy of skilled citizens to enter politics. Of the $\mu$ citizen who can potentially enter politics, all unskilled ones become party members while only a fraction of skilled ones do so. That is

$$
\left(A_{u}=\mu(1-s)\right) \wedge\left(A_{s}<\mu s\right)
$$

Concerning the equilibrium skill composition of party members (property 3), we observe that in principle, there are three other possible equilibrium situations alternative to the one we focus on.

i. Skilled citizens all become members, while some of the unskilled ones do not

$$
\left(A_{u}<\mu(1-s)\right) \wedge\left(A_{s}=\mu s\right)
$$

ii. All citizens, skilled and unskilled, become party members

$$
\left(A_{u}=\mu(1-s)\right) \wedge\left(A_{s}=\mu s\right)
$$


iii. Some skilled and unskilled citizens become members and some (both skilled and unskilled) do not

$$
\left(A_{u}<\mu(1-s)\right) \wedge\left(A_{s}<\mu s\right)
$$

However, there is no substantial loss of generality in focusing only on equilibria in which property 3 , page 11, holds. Indeed, as we show in section 5.5, in the equilibria in which property 3 does not hold so that skill composition of politicians matches one of the three possibilities describe above (associated with conditions 11-13), either the measure of parties is infinite or indeterminate or the case for a positive relationship between pay and quality of politicians (which is the focus of the paper) is even stronger.

In the following discussion, we will fully characterize the equilibrium that satisfies properties 1-3 listed above. Then we verify the parameter restrictions such an equilibrium exists. Since we are assuming symmetry, we drop the $k$ when referring to parties' actions.

\subsection{Citizens's behavior and equilibrium values of the probability to be elected}

We analyze first citizens' voting behavior (stage 5 of the citizen-parties game) and then their decision to become party members and engage in politics (stage 3 of the game).

Citizens vote based upon the set $\mathcal{C}$ of candidates, which coincides with the set of party members endowed with an individual informative signal $j$. Given $\mathcal{C}$, the optimal voting strategy of a citizen is as follows. Following the literature, we adopt the notion of conditional sincerity and assume noncandidate citizen perform as if they were pivotal.

That given, since citizens prefer skilled politicians and they observe a signal for each candidate, whenever such signal is informative $(\sigma>0.5)$ each non-candidate citizen votes for a randomly chosen element of the set of candidates with high-signal, $\mathcal{C}^{s}$, so long as such set is non-empty. Only if $\mathcal{C}^{s}$ were empty, would non-candidate citizen vote for a randomly drawn element of the set of candidates with signal $u, \mathcal{C}^{u}$. As for candidates, the optimal sub game perfect equilibrium strategy is as follows. Each candidate who - given the optimal voting strategy of non-candidates - has a positive positive probability to be elected votes for himself. As for candidates who have zero chance to be elected even if they vote for themselves, they will vote as non-candidate citizen.

Citizens' optimal behavior as voters allows us to characterize the equilibrium probabilities to be elected for candidates with signals $u$ and $s$, respectively. In particular, in any equilibrium in which condition (9) holds (property 2, page 11), so that there are enough candidates with a signal $s$ to cover all public office seats, a candidate with a signal $u$ will never be voted for public office, since citizens prefer skilled politicians. Accordingly, only candidates with signal $s$ would ever be elected if there are 
enough of them to cover all seats. ${ }^{11}$ Therefore, provided that such condition holds:

$$
\begin{aligned}
\alpha^{s} & =\frac{p}{C^{s}} \\
\alpha^{u} & =0
\end{aligned}
$$

are the equilibrium probabilities for a candidate to be elected conditional on her signal.

Substituting in for the values of $\alpha^{s}$ and $\alpha^{u}$ in the citizen's payoff expressions (2) and (3), the equilibrium expected gains from becoming party members, for citizens of type $s$ and $u$ are

$$
\left.v_{s}\right|_{d_{s}=1}-\left.v_{s}\right|_{d_{s}=0} \equiv \underbrace{\frac{p}{C^{s}} \sigma\left(\pi-w_{s}\right)}_{\text {Expected benefit }}-(\underbrace{\frac{p}{C^{s}} \sigma e_{s}+\phi}_{\text {Expected cost }})
$$

and,

$$
\left.v_{u}\right|_{d_{u}=1}-\left.v_{u}\right|_{d_{u}=0} \equiv \underbrace{\frac{p}{C^{s}}(1-\sigma)(\pi-1)}_{\text {Expected benefit }}-(\underbrace{\frac{p}{C^{s}}(1-\sigma) e_{u}+\phi}_{\text {Expected cost }})
$$

respectively.

The optimal decision about whether to become a party member and engage in politics $\left(d_{i}=1\right)$ or not, $\left(d_{i}=0\right)$, for a citizen of type $i$ is as follows,

$$
d_{i} \equiv \begin{cases}1 & \text { if }\left.v_{i}\right|_{d_{i}=1}-\left.v_{i}\right|_{d_{i}=0}>0 \\ 0,1 & \text { if }\left.v_{i}\right|_{d_{i}=1}-\left.v_{i}\right|_{d_{i}=0}=0 \\ 0 & \text { if }\left.v_{i}\right|_{d_{i}=1}-\left.v_{i}\right|_{d_{i}=0}<0\end{cases}
$$

Citizens net expected gain from becoming a party member and engaging in politics is given by the difference between an expected benefit and an expected cost. The expected gain is, for both skilled and unskilled citizens, a positive function of the probability to be elected and the difference between the reward as public officer and the salary in the private sector. The expected cost, for both skilled and unskilled citizens, is given by the sum of the participation cost and the expected service duties. Since in the equilibria we look at, only party members with signal $s$ have a positive probability to be elected, the net expected gains from entering politics are increasing (decreasing) in the informativeness, $\sigma$, of the signal for skilled (unskilled) citizens.

We note that, in the equilibrium we are interested in, the net expected gain from entering politics for skilled and unskilled citizen respectively should satisfy the following conditions. First, $\left.v_{u}\right|_{d_{u}=1}-$ $\left.v_{u}\right|_{d_{u}=0} \geq 0$ must hold, because if all unskilled decide to become party members, this should be the preferred choice for this type of citizens. Second, $\left.v_{s}\right|_{d_{s}=1}-\left.v_{s}\right|_{d_{s}=0}=0$ must hold, because skilled citizens must be indifferent between becoming party members or not, in order for only a fraction of skilled individuals to choose to become party members. ${ }^{12}$

\footnotetext{
${ }^{11}$ Note that if there are enough candidates with signal $j=s$ to cover all seats $\left(C^{s}>p\right.$, property 2$)$, in general, in order to be elected a candidate needs more than one vote, so that even though each candidate with signal $u$ votes for himself, this would be not enough for such candidates to be elected.

${ }^{12}$ Since all skilled citizens share the same payoff function, if $\left.v_{s}\right|_{d_{s}=1}-\left.v_{s}\right|_{d_{s}=0}>0$, then all skilled citizens would be willing to run while if $\left.v_{s}\right|_{d_{s}=1}-\left.v_{s}\right|_{d_{s}=0}<0$ none of them will be willing to become party members.
} 
Crucially, since only party members with signal $s$ have a positive probability of being elected, the measure of candidates with a positive chance to be elected will be given by the sum of skilled party members with correct signal and of unskilled party members with incorrect signal. More precisely

$$
\begin{aligned}
C_{s}^{s} & =\sigma A_{s} \\
C_{u}^{s} & =(1-\sigma) A_{u}
\end{aligned}
$$

In the class of equilibria we restrict attention to, where unskilled citizens all become party members, we also have

$$
C_{u}^{s}=\mu(1-s)(1-\sigma)
$$

And since $C^{s}=C_{s}^{s}+C_{u}^{s}$, in our equilibrium the probability of being elected reduces to

$$
\alpha^{s}=\frac{p}{C_{s}^{s}+\mu(1-s)(1-\sigma)}
$$

where the value of $C_{s}^{s}$ will be pinned down endogenously from parties optimal behavior as analyzed in the next subsection.

\subsection{Parties' behavior}

In this subsection we analyze parties' equilibrium choice of service duties, $e_{i}$ (stage 4 of the citizenparty game) to be extracted from skilled and unskilled politicians, $i=s, u$, and of the optimal degree of information manipulation, $\sigma$, (stage 4 of the game) for a given measure of parties $N$. Then, the entry decision will be dealt with. We assume perfect enforceability of service duties, $e_{i}{ }^{13}$ As we shall see, the optimal value of $e_{i}$ together with the conditions relative to citizens' optimal behavior, pins down the probabilities of being elected and the measure of candidates as well as its skill composition.

\subsubsection{Equilibrium values of the service duties, $e_{s}$ and $e_{u}$, and of the measure of candi- dates with positive chance to be elected, $C^{s}$}

The following result holds,

Lemma 1. Consider a symmetric equilibrium in which the equilibrium measure of parties is finite, $N^{*}<\infty$, and determinate. Then $e_{u}^{*}>e_{s}^{*}=0$.

Proof. We prove this result by contradiction. Consider a candidate equilibrium where $e_{s}^{*}>0$. In this case, by (6) and irrespective of the value of $e_{u}^{*}$, parties could make strictly positive profits by setting $\sigma=\bar{\sigma}$ such that $c(\bar{\sigma})=0$. But then in this case, an equilibrium where parties make zero profits is only compatible with $N^{*}=\infty$, which contradicts the hypothesis of a finite measure for the measure of parties. Hence, $N^{*}<\infty$ implies $e_{s}^{*}=0$. Now, suppose that $e_{u}^{*}=0$. Since $N<\infty$ implies $e_{s}^{*}=0$, then parties can make non-negative profits only by choosing $\sigma^{*}=\bar{\sigma}$. However in this case, profits would always be zero and therefore the measure of parties would be indeterminate in equilibrium.

\footnotetext{
${ }^{13}$ Otherwise, incentives for elected politicians to pay service duties to the party should be modeled explicitly. One could assume that parties can impose penalties on politicians who refuse to pay. In a repeated interaction framework the threat of excluding them from future elections could be such penalty. Otherwise we could assume that service duties have to be paid upfront when a party member becomes candidate, which would not change the results.
} 
The above result tells us that in equilibria where the measure of parties is finite and determinate, parties are able to extract positive service duties only from unskilled politicians. If this were not the case, then either $e_{u}^{*}=e_{s}^{*}=0$, in which case the equilibrium measure of parties would be indeterminate, or $e_{s}^{*}>0$, in which case the equilibrium measure of parties is infinite. We would like to emphasize that this equilibrium feature holds irrespectively of whether properties 2 and 3 on page 11 hold or not.

Regarding the optimal value of service duties charged to unskilled politicians, $e_{u}^{*}$, and the equilibrium measure of candidates with a positive chance to be elected, $C^{s *}$, the following result holds,

Lemma 2. Consider an equilibrium in which properties 1-3 on page 11 are satisfied, and the equilibrium measure of parties is finite, $N^{*}<\infty$. Then

$$
\begin{aligned}
e_{u}^{*} & =\max \left[0, \frac{(1-\sigma)(\pi-1)-\sigma\left(\pi-w_{s}\right)}{(1-\sigma)}\right] \\
C^{s *} & =\frac{p \sigma\left(\pi-w_{s}\right)}{\phi}
\end{aligned}
$$

Proof. We restrict our attention on a case where $N^{*}<\infty$, so that lemma 1 holds and $e_{s}^{*}=0$. First of all, we note that, in any equilibrium, parties are local monopolists when setting service duties since they take such decision once citizen have become party members, and party members face an infinite cost of switching party. Therefore, the best strategy of party $k$ is always to charge the maximum feasible party duties (above which party members would quit politics), thereby extracting all the expected surplus that the citizen makes by choosing to engage in politics, i.e. $e_{i}^{*}:\left.v_{i}\right|_{d_{i}=1}-\left.v_{i}\right|_{d_{i}=0}=0$, where $\left.v_{i}\right|_{d_{i}=1}$ is the payoff of a party member who engages in politics as defined by equation (2) and $\left.v_{i}\right|_{d_{i}=0}$ is the payoff of a party member who decides to quit politics (3). Using $e_{s}^{*}=0$ in (16), setting $\left.v_{s}\right|_{d_{s}=1}-\left.v_{s}\right|_{d_{s}=0}=0$, we find $C^{s *}=\frac{p \sigma\left(\pi-w_{s}\right)}{\phi}$. Substituting for this value for $C^{s *}$ into $(17)$ and setting $\left.v_{u}\right|_{d_{u}=1}-\left.v_{u}\right|_{d_{u}=0}=0$ we obtain $e_{u}^{*}=\frac{(1-\sigma)(\pi-1)-\sigma\left(\pi-w_{s}\right)}{(1-\sigma)}$. Since $e_{u}$ cannot be negative (parties cannot make negative profits in equilibrium), its equilibrium value is the maximum between 0 and

$\frac{(1-\sigma)(\pi-1)-\sigma\left(\pi-w_{s}\right)}{(1-\sigma)}$. Note that according to lemma $1, e_{u}$ is necessarily positive only if the equilibrium measure of parties is determinate.

Having analyzed the equilibrium service duties, we now turn our attention to parties' information manipulation.

\subsubsection{Information manipulation: Optimal choice of $\sigma$ by parties}

Given Lemma 1 , in any equilibrium with a determined and finite measure of parties, $N^{*}, e_{s}^{*}=0$ and $e_{u}^{*}>0$ should hold. Then, the following result follows from lemmata 1-2 regarding the optimal choice of $\sigma$ by parties,

Corollary 1. Consider an equilibrium in which properties 1-3 on page 11 are satisfied and the equilibrium measure of parties is finite, $N^{*}<\infty$, and determinate. Then the optimal degree of information manipulation chosen by parties must be such that

$$
\sigma^{*}<\hat{\sigma} \equiv \frac{\pi-1}{\pi-w_{s}+\pi-1}
$$

Proof. By lemma 1 we know that $N^{*}<\infty$ and determinate imply $e_{u}^{*}>0$. Furthermore, given the expression for $e_{u}^{*}$ (lemma 2, equation 23), $e_{u}^{*}>0$ implies $\sigma^{*}<\hat{\sigma} \equiv \frac{\pi-1}{\pi-1+\pi-w_{s}}$. 
The above corollary introduces an important parameter in our analysis, $\hat{\sigma}$, which represents the level of informativeness of the public signal above which skilled citizens are more willing to become party members than unskilled one.

It is interesting to note that $\hat{\sigma}$ is always decreasing in $\pi$ since

$$
\frac{\partial \hat{\sigma}}{\partial \pi} / \hat{\sigma}=\frac{1-w_{s}}{\left(\pi-1+\pi-w_{s}\right)(\pi-1)}<0
$$

The intuition for this outcome is straightforward. When the level of informativeness of the signal equals $\hat{\sigma}$ skilled and unskilled citizens are equally willing to enter politics. Whenever the signal is informative an increase in pay of politicians favors more skilled party members than unskilled ones, since the former have a higher chance to be elected than the latter. To compensate this effect, as the pay of politicians increases, the value of $\hat{\sigma}$ should go down, thereby increasing the chance of unskilled party members to be elected.

Given corollary 1, we study the optimal choice of $\sigma$ under the hypothesis that such choice satisfies $\sigma^{*}<\hat{\sigma}$, which is necessary in order for the equilibrium measure of parties to be finite and determinate. We will later verify (see section 5.5) the sufficient conditions under which such hypothesis is confirmed.

Combining (24) and (14) we obtain the probability of being elected as a function of only one endogenous variable, $\sigma$ :

$$
\alpha^{s}=\frac{\phi}{\sigma\left(\pi-w_{s}\right)}
$$

Under the hypothesis that $\sigma^{*}<\hat{\sigma}$ (corollary 1), using lemmata 1-2 to substitute for the equilibrium values of $e_{s}, e_{u}, C^{s}, \alpha^{s}$ and $\alpha^{u}$ in (6), and considering that in a symmetric equilibrium each party is identical, the representative party solves

$$
\max _{\sigma} \frac{\phi \mu(1-s)}{N}\left(\frac{\pi-1}{\pi-w_{s}} \frac{1-\sigma}{\sigma}-1\right)-c(\sigma)
$$

In the case of an interior solution, for given $N$, the optimal level of $\sigma$, which we call $\sigma^{*}$, solves the following first-order condition

$$
-\frac{\phi \mu(1-s)}{N} \frac{\pi-1}{\pi-w_{s}}-\sigma^{2} c^{\prime}(\sigma)=0
$$

A rise in $\sigma$ has two opposing effects on the party's objective function. The positive effect stems from a lower cost of information manipulation (remember $c^{\prime}(\sigma)<0$ so that $\left.-\sigma^{2} c^{\prime}(\sigma)>0\right)$. This effect is associated with the second term on the LHS of equation (29). The negative effect is given by the first term on the LHS of (29). A lower degree of information manipulation reduces the amount of service duties that a party can extract from politicians. That happens because of two main forces: 1) The equilibrium measure of unskilled politicians is reduced (both because more skilled citizens are becoming party members and because the probability of being elected for a low-type/high-signal party member is reduced); 2) The maximum level of service duties each unskilled politician is willing to contribute is lower because the expected net gains from politics are reduced.

The optimal level of $\sigma$ is the one that balances the two effects. Before introducing an explicit cost function in order to fully characterize the optimal value of $\sigma^{*}$ and find the parameter restrictions 
under which the hypothesis $\sigma^{*}<\hat{\sigma}$ holds, we first analyze how the equilibrium measure of parties $N^{*}$ is determined.

\subsection{Measure of parties and informativeness of the public signal}

We assume free entry for parties (stage 2 of the game). Accordingly, the following result holds

Lemma 3. Consider an equilibrium in which properties 1-3 on page 11 are satisfied, and the equilibrium measure of parties is determined. Then, for given $\sigma$, the equilibrium measure of parties, $N^{*}$, satisfies,

$$
N^{*}=\frac{1}{c(\sigma)}\left(\phi \mu(1-s)\left(\frac{\pi-1}{\pi-w_{s}} \frac{1-\sigma}{\sigma}-1\right)\right) .
$$

Proof. For given $\sigma, N^{*}$, is found by: (i) substituting in equation (6) for the equilibrium values of $e_{s}$, $e_{u}, \alpha_{s}, \alpha_{u}, A_{k, u}$, and $A_{k, s}$, then; (ii) imposing free entry, which implies $v_{k}=0$, and; (iii) solving for $N$.

The equilibrium measure of parties, $N^{*}$, and the equilibrium value of informativeness of the public signal, $\sigma^{*}$, associated with information manipulation by parties, are found solving the simultaneous system of equations (29) and (30). By substituting for $N^{*}$ in (29) using (30), we get

$$
\sigma^{*}: \frac{\hat{\sigma}}{\hat{\sigma}-\sigma^{*}}=-\frac{\sigma^{*} c^{\prime}\left(\sigma^{*}\right)}{c\left(\sigma^{*}\right)}
$$

which defines implicitly the equilibrium value for $\sigma$, equal to $\sigma^{*}$, as a function of $\hat{\sigma}$ and therefore of $\pi$ and $w_{s}$ only (see equation (25)). Having characterized the equilibrium that satisfies properties $1-3$, we now turn to the analysis of the relevant existence conditions.

\subsection{Sufficient conditions for Equilibrium existence}

For the value $\sigma^{*}$ to yield a maximum, we require party's objective function (28) to be globally strictly convex in $\sigma \in(0.5, \bar{\sigma})$ which in turn requires

$$
\frac{2}{\sigma^{3}} \frac{A_{u}}{N} \phi \frac{\pi-1}{\pi-w_{s}}-c^{\prime \prime}(\sigma)<0, \forall \sigma \in(0.5, \bar{\sigma})
$$

Substituting in using (29) the above condition reduces to the following assumption

Assumption 1. $-\frac{\sigma c^{\prime \prime}(\sigma)}{c^{\prime}(\sigma)}=\gamma(\sigma)>2$, for $\sigma \in(0.5, \bar{\sigma})$.

Assumption 1 states that the elasticity of the marginal cost of manipulating information should be large enough for a unique optimal value $\sigma^{*} \in(0.5, \bar{\sigma})$ to exist. ${ }^{14}$

Apart from Assumption 1, in order for $\sigma^{*}$ to be consistent with properties 1-3 of the equilibrium, we need some other restrictions on parameters' values to be satisfied. First, since the equilibrium value of $C^{s}$ is given by (24), property 2 on page 11 (i.e. $C^{s}>p$ ) implies $\sigma^{*}>\frac{\phi}{\pi-w_{s}}$ should hold.

\footnotetext{
${ }^{14}$ This follows from the fact that if assumption 1 holds, then $\sigma^{2} c^{\prime}(\sigma)$ is strictly decreasing and so there is only one value of $\sigma$ that satisfies the first-order condition (29).
} 
In turn, since $\sigma^{*}>0.5$ must hold, as we want the signal produced by parties to be informative, a sufficient condition for $C^{s}>p$ to hold in equilibrium is,

$$
\phi<\frac{\pi-w_{s}}{2}
$$

That is, in order to have enough candidates of high signal to cover all seats in equilibrium, the participation cost should not be too large.

Second, property 3, page 11, requires that only a fraction of skilled citizens become party members, that is $A_{s}<\mu s$. Given that in the equilibrium we are analyzing, (i) the measure of candidates with high signal is equal to the sum of skilled party members with correct signal and unskilled party members with incorrect signal, and (ii) all unskilled citizens become party members, then

$$
C^{s}=\sigma A_{s}+(1-\sigma)(1-s) \mu
$$

so that the measure of skilled party members can be written as

$$
A_{s}=\frac{C^{s}-(1-\sigma)(1-s) \mu}{\sigma}
$$

Substituting in for the equilibrium value of $C^{s}$ as given by (24), we conclude that property 3 is satisfied when

$$
\frac{\frac{\sigma^{*} p\left(\pi-w_{s}\right)}{\phi}-\left(1-\sigma^{*}\right)(1-s) \mu}{\sigma^{*}}<\mu s
$$

which implicitly sets an upper bound for the equilibrium value of $\sigma^{*}$, i.e.

$$
\sigma^{*}<\frac{(1-s) \mu \phi}{p\left(\pi-w_{s}\right)+\mu \phi(1-2 s)},
$$

Finally, since we need $\sigma^{*} \in\left(\frac{1}{2}, \hat{\sigma}\right)$, the above inequality is satisfied if

$$
\hat{\sigma}<\frac{(1-s) \mu \phi}{p\left(\pi-w_{s}\right)+\mu \phi(1-2 s)}
$$

or, given the value of $\hat{\sigma}=\frac{\pi-1}{\pi-1+\pi-w_{s}}$, if,

$$
\phi>\frac{p\left(\pi-w_{s}\right)(\pi-1)}{\mu\left(\left(\pi-w_{s}\right)+s\left(w_{s}-1\right)\right)}
$$

The above condition sets an upper bound for $\phi$. The cost of becoming party member cannot be too large in an equilibrium where only a fraction of skilled citizens become party members while all unskilled citizens do so.

Given the other parameters, we can summarize the restrictions on the value of $\phi$ that constitute necessary and sufficient for the existence of the equilibrium that satisfies properties 1-3, as follows

Assumption 2. $\phi \in\left(\frac{p}{\mu} \frac{\left(\pi-w_{s}\right)(\pi-1)}{\left(\pi-w_{s}\right)+s\left(w_{s}-1\right)}, \frac{\pi-w_{s}}{2}\right)$. 
It is important to notice that when $p / \mu$ (i.e. the ratio between the measure of political seats and the measure of citizens who can potentially become politicians) is small enough, then there is a wide range of values of $\phi$ such that - given the other parameters - assumption 2 is satisfied and our equilibrium exists.

Finally, the following further assumption is needed in order to ensure that an equilibrium with finite and determinate measure of parties $N^{*}$ exists and $\sigma^{*}<\hat{\sigma}$ always holds in such an equilibrium (see corollary 1),

Assumption 3. $\bar{\sigma}>\hat{\sigma} \equiv \frac{\pi-1}{\pi-1+\pi-w_{s}}$.

This assumption ensures that in equilibrium parties' revenues don't exceed parties' costs for any $\sigma \in(0.5, \bar{\sigma})$ and they are equalized only when $\sigma=\sigma^{*}$ where, by definition, parties maximize their profit and make zero profit as well. ${ }^{15}$

It follows directly from the above discussion that, given the other parameters, if $\phi, \gamma$, and $\sigma$ satisfy assumptions 1, 2 and 3, the equilibrium we are interested in, which satisfies properties 1-3, exists and it is unique.

\subsection{Skill composition of party members: A discussion of potential equi- librium alternatives}

In the previous section, we have focused on equilibria where property 3 holds, i.e., all unskilled citizens become party member while only a fraction of skilled ones do so. In this section we explain why such choice does not entail a significant loss of generality, given the focus of the paper. As already discussed on page 12, as far as the equilibrium skill composition of party members goes, there are three alternatives other than the one we focus on. We could have that skilled citizens all become members, while some of the unskilled ones do not (case i), or all skilled and unskilled citizens become members (case ii), or finally that some skilled and unskilled citizens become members and some (both skilled and unskilled) do not (case iii).

In any equilibrium characterized by the skilled composition associated with case i above, skilled citizens must be more willing to enter politics than unskilled ones, which would imply $e_{s}^{*}>e_{u}^{*} \geq 0$. However, from lemma 1 , we know that $e_{s}^{*}>0$ is only compatible with $\sigma^{*}=\bar{\sigma}$. We conclude that in this kind of equilibria, the level of information is always set at the maximum level $\bar{\sigma}$ and the measure of parties is infinite, i.e. $N^{*}=\infty$. This makes the analysis of this equilibrium rather uninteresting.

${ }^{15}$ From (28), we can rewrite the profit function of the party as

$$
B(\sigma)-c(\sigma)
$$

where $B(\sigma)$ represents the party's revenue and can be written as $B(\sigma)=\frac{\mu \phi(1-s)}{N} \frac{\pi-1}{\pi-w_{s}}\left(\frac{1}{\hat{\sigma}}-\frac{1}{\sigma}\right)$. Now notice that $B(\sigma)$ is strictly decreasing $\left(\frac{\partial B}{\partial \sigma}<0\right)$ and strictly globally convex $\left(\frac{\partial^{2} B}{\partial \sigma^{2}}>0\right)$ in $\sigma$. Since this is also the case for $c(\sigma)$ (see section 3.2), then it is straightforward to conclude that, due to free entry, $B(\sigma) \leq c(\sigma)$ for every $\sigma \in(0.5, \bar{\sigma})$ with $B(\sigma)=c(\sigma)$ only for $\sigma^{*}=\sigma<\hat{\sigma}$. But then it must also be $c(\hat{\sigma})>B(\hat{\sigma})=0$ where the latter equality stems from the fact that when $\hat{\sigma}=\sigma$ then $e_{u}=e_{s}=0$ so that parties make zero profits. But since $c(\cdot)$ is assumed to be continuous in $(0.5, \bar{\sigma})$ and monotonically decreasing in $\sigma,\left(c^{\prime}(\sigma)<0\right)$, then it must be $\hat{\sigma}<\bar{\sigma}$ which corresponds to assumption 3. For a graphical representation of the above argument see also figure 3 . 
As for equilibria which correspond to case ii above in terms of skill composition, it is easy to see that in such equilibria $e_{s}^{*}$ is always strictly positive (and then the equilibrium measure of parties $N^{*}$ is infinite) except for a specific value of $\sigma^{*}$, for which $e_{s}^{*}=0$. When all citizens, both skilled and unskilled, become party member, then $C^{s}=\mu \sigma s+\mu(1-\sigma)(1-s)$. But then, from (16) and imposing $\left.v_{s}\right|_{d_{s}=1}-\left.v_{s}\right|_{d_{s}=0}=0$, we obtain

$$
e_{s}=\pi-w_{s}-\frac{\phi C^{s}}{p \sigma}
$$

Now, by substituting for $C^{s}=\mu \sigma s+\mu(1-\sigma)(1-s)$, we can conclude that in this case $e_{s}^{*}=0$ if and only if $\sigma^{*}=\frac{(1-s) \mu \phi}{p\left(\pi-w_{s}\right)+\mu \phi(1-2 s)}$. For this reason, the loss of generality in disregarding this kind of equilibria is negligible.

Finally, in any equilibrium that falls under case iii above in terms skill composition of party members, we would always have $e_{s}^{*} \leq e_{u}^{*}$. Lemma 1 applies so that $e_{s}^{*}=0$ must hold for the measure of parties to be finite. In this case, we could have either $e_{u}^{*}=0$ (but then by lemma 2 the measure of parties would be indeterminate and the equilibrium analysis uninteresting) or $e_{u}^{*}>0$, in which case the measure of parties could be determined. Note that, in this case, $\sigma^{*}<\hat{\sigma}$ (given corollary 1 , which also holds in this case). The main features of this equilibrium would then be similar to the ones associated with the equilibrium we focus on hold, with an important difference. In the equilibrium we focus on, all unskilled citizens are already in politics. Differently, in this types of equilibrium, some of the unskilled are outside politics. Therefore, an increase in the pay of politicians could attract more unskilled citizens into politics. Something that cannot happen in the case we focus on, in which an increase in the pay of politicians could only attract skilled citizens into politics if any. Because of that, the case for a negative relationship between pay and quality of politicians is even stronger than in the type of equilibria we focus. Therefore, by adopting a conservative approach, we could disregard this type of equilibria.

Given the above discussion, the choice to focus on equilibria that satisfy property 3 on page 11 seems entirely appropriate and brings no significant loss of generality.

\subsection{Equilibrium characterization with an explicit cost function}

We now fully characterize the equilibrium by assuming the following explicit cost function

$$
c(\sigma)=\left(\frac{\bar{\sigma}-\sigma}{\sigma}\right)^{\theta}
$$

Notice that in this case, assumption 1 requires that $\theta>1$. As for $\bar{\sigma}$, the only relevant case by assumption 3 is the one in which $\bar{\sigma}>\hat{\sigma}>0.5$ holds, where we recall that $\bar{\sigma}$, measures the quality of the public signal about candidates' type produced in the absence of information manipulation by parties. Given (40), condition (31) can be solved for $\sigma^{*}$ yielding,

$$
\sigma^{*}=\frac{\bar{\sigma}}{\theta \bar{\sigma}-\hat{\sigma}} \hat{\sigma}(\theta-1)
$$

Given $\theta>1, \theta \bar{\sigma}>\bar{\sigma}>\hat{\sigma}$ follows, implying $\sigma^{*}<\hat{\sigma}$, which ensures that $\sigma^{*}$ is consistent with the existence of the type of equilibrium we focus on. Moreover, for $\sigma^{*}>0.5$ to hold, we need to impose 
the additional following restriction on $\theta$,

$$
\theta>\frac{\hat{\sigma}(2 \bar{\sigma}-1)}{\bar{\sigma}(2 \hat{\sigma}-1)}>1
$$

If this were not the case, then manipulating information would be so cheap that parties would always choose the minimum level of information manipulation. ${ }^{16}$ The associated value of $N^{*}$ is found substituting for the value of $\sigma$ in equation (30) using the above explicit solution for $\sigma^{*}$.

Having fully characterized the equilibrium, we can now turn to the analysis of how changes in the pay of politicians affect the quality of elected politicians.

\section{Quality of politicians and politicians' pay}

Given the model setup, the relevant measure of quality of politicians, $q$, is the fraction of politicians of type $s$, which affects the level of taxes necessary to finance the provision of the public good. In a symmetric equilibrium - by the law of large numbers - the fraction of politicians of type $s$ is the same as the fraction of skilled candidates endowed with signal $s$. That is, $q=\frac{C_{s}^{s}}{C^{s}}$ holds. Using (24), and recalling that $C_{s}^{s}=C^{s}-\mu(1-s)(1-\sigma)$ we finally obtain the equilibrium value of $q$

$$
q^{*}=1-\frac{\mu(1-s)\left(1-\sigma^{*}\right)}{C^{s *}}=1-\frac{\phi \mu(1-s)\left(1-\sigma^{*}\right)}{p \sigma^{*}\left(\pi-w_{s}\right)}
$$

as a function of the equilibrium value of the quality of public information, $\sigma^{*}$. In order to see how politicians' pay affects quality of politicians we differentiate $q^{*}$ with respect to $\pi$,

$$
\frac{\partial q^{*}}{\partial \pi}=\frac{\phi \mu(1-s)}{p \sigma^{*}\left(\pi-w_{s}\right)}(\underbrace{\frac{1-\sigma^{*}}{\pi-w_{s}}}_{\text {Selection effect }}+\underbrace{\frac{\partial \sigma^{*}}{\partial \pi} \frac{1}{\sigma^{*}}}_{\text {Information manipulation effect }})
$$

The effect of pay on quality can be viewed as the sum of two different effects: (i) A Selection effect and; (ii) An information manipulation effect. The first effect - which is always positive - is the one put forward by Caselli and Morelli, 2004. An increase in $\pi$ attracts skilled citizens into politics which, other things equal, improves the quality of party members, candidates and elected politicians. The second effect is novel and it has to do with the fact that increase in the pay of politicians, might induce parties to change their propensity to manipulate information about candidates. Crucially, the following result holds regarding the sign of the information manipulation effect,

Lemma 4. Consider an equilibrium in which properties 1-3 on page 11 are satisfied and the equilibrium measure of parties is finite, $N^{*}<\infty$, and determinate. Then, an increase in the pay of politicians induces parties to manipulate information more. That is,

$$
\frac{\partial \sigma^{*}}{\partial \pi} \frac{1}{\sigma^{*}}<0
$$

\footnotetext{
${ }^{16}$ It is easy to note that $\sigma^{*}$ is, quite intuitively, decreasing in $\theta$.
} 
Proof. Rewriting condition (31) as follows

$$
c\left(\sigma^{*}\right) \hat{\sigma} \equiv-\left(\hat{\sigma}-\sigma^{*}\right) \sigma^{*} c^{\prime}\left(\sigma^{*}\right)
$$

Applying the implicit function theorem by differentiating both sides of the latter expression with respect to $\sigma$ and $\pi$ and solving for $\frac{\partial \sigma^{*}}{\partial \pi}$ yields

$$
\frac{\partial \sigma^{*}}{\partial \pi}=\frac{c\left(\sigma^{*}\right)}{\left(\hat{\sigma}-\sigma^{*}\right)\left(\gamma\left(\sigma^{*}\right)-2\right) c^{\prime}\left(\sigma^{*}\right)} \frac{\partial \hat{\sigma}}{\partial \pi}\left(\frac{\sigma^{*} c^{\prime}\left(\sigma^{*}\right)}{c\left(\sigma^{*}\right)}+1\right)
$$

where $\gamma\left(\sigma^{*}\right)=-\frac{\sigma^{*} c^{\prime \prime}\left(\sigma^{*}\right)}{c^{\prime}\left(\sigma^{*}\right)}$ is the elasticity of the marginal cost of manipulating information evaluated at the equilibrium value of $\sigma^{*}$. Finally, substituting in using equation (31) we find

$$
\frac{\partial \sigma^{*}}{\partial \pi} / \sigma^{*}=\frac{\sigma^{*}}{\hat{\sigma}-\sigma^{*}} \frac{1}{\gamma\left(\sigma^{*}\right)-2} \frac{\partial \hat{\sigma}}{\partial \pi} / \hat{\sigma}
$$

which is clearly negative since: 1$)$ by $(26), \frac{\partial \hat{\sigma}}{\partial \pi} / \hat{\sigma}$ is negative; 2$)$ by the second-order condition, $\gamma\left(\sigma^{*}\right)>$ $2 ; 3)$ in the interior solution $\hat{\sigma}>\sigma^{*}$.

Why does an increase in politicians' reward always induce parties to manipulate information more? The intuition can be gained from figure 3 that shows the equilibrium expected benefits $B(\sigma ; \pi)$ and $\operatorname{costs} c(\sigma)$ of a representative party as a function of $\sigma \in(0.5, \bar{\sigma})$ for two different values of politicians' pay equal to $\pi_{0}$ and $\pi_{1}$ respectively, with $\pi_{0}<\pi_{1}$. Notice that while $c(\sigma)$ does not depend on politicians' pay, $\pi, B(\sigma ; \pi)$ does depend on it, because a change in $\pi$ affects both the equilibrium level of service duties to be paid by unskilled politicians, $e_{u}$, as well as and the skill composition of politicians belonging to each party.

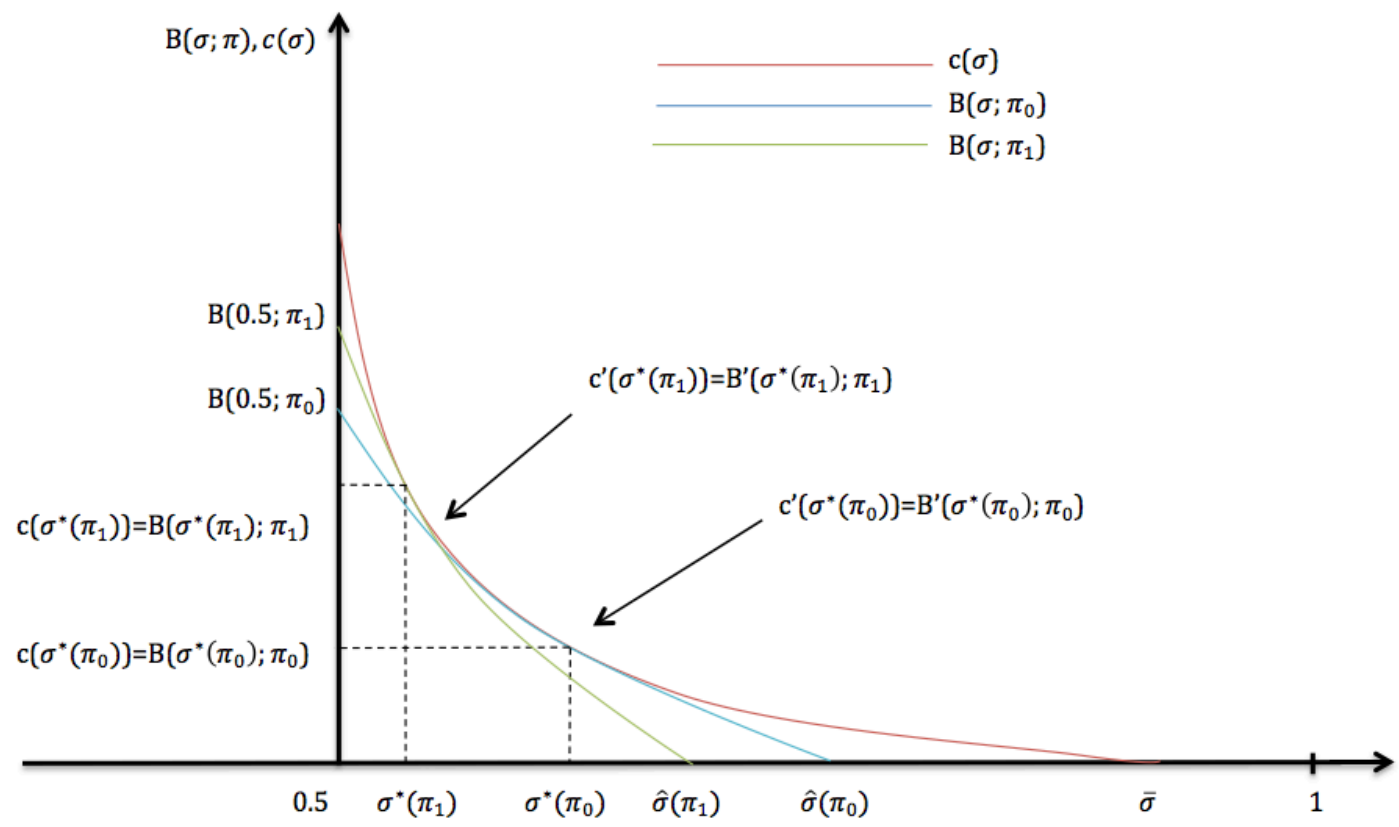

Figure 3: The information manipulation effect: change in the optimal solution of $\sigma$ following an increase in $\pi$. 
For $\pi=\pi_{0}$, the optimal choice $\sigma^{*}\left(\pi_{0}\right)$ corresponds to the tangency point of the benefit curve $B\left(\sigma ; \pi_{0}\right)$ and the cost curve $c(\sigma)$. Notice that at $\sigma^{*}\left(\pi_{0}\right)$ total costs equal total benefits, i.e. $B\left(\sigma^{*}\left(\pi_{0}\right) ; \pi_{0}\right)=$ $c\left(\sigma^{*}\left(\pi_{0}\right)\right)$, and marginal costs equal marginal benefits, i.e. $B^{\prime}\left(\sigma^{*}\left(\pi_{0}\right) ; \pi_{0}\right)=c^{\prime}\left(\sigma^{*}\left(\pi_{0}\right)\right) .{ }^{17}$ The horizontal intercept for the costs curve is $\bar{\sigma}$, which is the quality of public information in the absence of parties' interference, in which case parties incur no cost, i.e. $c(\bar{\sigma})=0$. The horizontal intercept for the benefits curve is by contrast $\hat{\sigma}\left(\pi_{0}\right)=\frac{\pi_{0}-1}{\pi_{0}-1+\pi_{0}-w_{s}}$, which is the quality of information such that, for $\pi=\pi_{0}$, the maximum service duties that can be charged from unskilled politicians equal those that can be charged to skilled politicians. Since in this type of equilibrium $e_{s}=0$, then $e_{u}\left(\hat{\sigma}\left(\pi_{0}\right)\right)=0$ and therefore $B\left(\hat{\sigma} ; \pi_{0}\right)=e_{u}\left(\hat{\sigma}\left(\pi_{0}\right)\right) \alpha^{s}\left(\hat{\sigma}\left(\pi_{0}\right)\right)\left(1-\hat{\sigma}\left(\pi_{0}\right)\right)=0$. Note that, by construction, the horizontal intercept of $c(\sigma)$, i.e. $\bar{\sigma}$, must be strictly larger than the horizontal intercept of $B(\sigma ; \cdot)$, i.e. $\hat{\sigma}(\cdot)$, thus respecting Assumption 3.

Now assume an exogenous increase in politicians' reward from $\pi_{0}$ to $\pi_{1}>\pi_{0}$. The costs curve remains unaffected while the benefits curve tilts clockwise becoming steeper. The movement of the benefits curve can be explained as follows. First, party's marginal benefits of manipulating information are increased at any level of $\sigma$ and, second, unskilled politicians are less willing to run for public office so that the threshold $\hat{\sigma}$ falls. As a result, the "old" equilibrium value $\sigma^{*}\left(\pi_{0}\right)$ is not optimal anymore, because, according to the new benefits curve $B\left(\sigma ; \pi_{1}\right)$, at $\sigma^{*}\left(\pi_{0}\right)$, marginal benefits are larger than the marginal costs, i.e. $-B^{\prime}\left(\sigma^{*}\left(\pi_{0}\right) ; \pi_{1}\right)>-c^{\prime}\left(\sigma^{*}\left(\pi_{0}\right)\right)$, and total benefits are smaller than total costs $\left(B\left(\sigma^{*}\left(\pi_{0}\right) ; \pi_{1}\right)<c\left(\sigma^{*}\left(\pi_{0}\right)\right)\right)$. In order to restore optimality parties manipulate information more. In other words, the optimal value of $\sigma$ is now $\sigma^{*}\left(\pi_{1}\right)<\sigma^{*}\left(\pi_{0}\right)$, which is associated to higher marginal and absolute costs (since $c^{\prime \prime}(\sigma)>0$ and $c^{\prime}(\sigma)<0$ ) and higher marginal and absolute benefits. Hence, lemma 4 holds: an increase in pay of politicians is associated with more information manipulation by parties.

The fact that unskilled citizens' willingness to run for office is reduced in spite of an increase in $\pi$ is counterintuitive and deserves an explanation. For given skill composition of politicians, an increase in $\pi$ makes it more attractive for unskilled politicians to enter politics, which should increase the service duties they can be charged. However, following the increase in $\pi$, more skilled citizens decide to enter politics, and this reduces the chances of election for unskilled candidates so much, that the expected benefits for an unskilled citizen who decides to enter politics are reduced. ${ }^{18}$

Then, the question is how to reconcile an increase in absolute and marginal benefits of manipulating information following an increase in politicians' rewards, given that a smaller propensity of unskilled citizens to become party members implies smaller service duties that can be charged to them. In other words, why do parties want to incur higher costs of information manipulation if the service duties they can charge are reduced? Here the role of parties' free entry is crucial. By reducing absolute benefits due to the adverse effect on service duties while leaving absolute costs unchanged (for a given $\sigma$ ), an increase in $\pi$, reduces the equilibrium measure of parties $\left(N^{*}\left(\pi_{1}\right)<N^{*}\left(\pi_{0}\right)\right)$, which in turns increases

\footnotetext{
${ }^{17}$ Also notice that, due to free entry, party's expected profits are zero and this is why the costs curve always lies above the benefits curve except in correspondence with the optimal value.

${ }^{18} \mathrm{By}$ the way, this confirms that the type of equilibrium we focus on is the one in which it is more difficult for an increase in $\pi$ to result in a reduction of the quality of politicians. This is because in all other types of equilibria the change in skill composition following an increase in $\pi$ is either absent or ineffective.
} 
total and marginal benefits of manipulating information for incumbent parties.

To sum-up, the information manipulation effect can be explained as follows. An increase in politicians' pay, $\pi$, increases the measure of skilled citizens who become party members. Since parties can charge higher service duties to unskilled politicians than to skilled ones, they are more willing to bear the cost of manipulating information even further. The overall effect of increasing the pay of politicians on quality of politicians is the result of the tradeoff between the selection effect and the information effect. Increasing politicians' pay always lead to more information manipulation by parties, according to lemma 4, which -other things equal- would increase the chance of election for unskilled party members, thereby reducing politicians' quality. Therefore, for an increase in politicians' pay to improve the quality of elected politicians, the selection effect should be strong enough, as we explore in the next subsection by resorting to the full characterization of the equilibrium under the cost function (40).

\subsection{Pay and quality of politicians with a specific cost function}

Given the cost function, (40), the expression for the information manipulation effect can be obtained by differentiating (41) with respect to $\pi$, which yields

$$
\frac{\partial \sigma^{*}}{\partial \pi} \frac{1}{\sigma^{*}}=\frac{\theta \bar{\sigma}}{\theta \bar{\sigma}-\hat{\sigma}} \frac{\partial \hat{\sigma}}{\partial \pi} \frac{1}{\hat{\sigma}}
$$

where $\frac{\partial \hat{\sigma}}{\partial \pi} \frac{1}{\hat{\sigma}}$ is defined by (26). The following results holds

Proposition 1 (Pay and quality of politicians). Consider an equilibrium in which properties 1-3 on page 11 are satisfied and the equilibrium measure of parties is finite, $N^{*}<\infty$, and determinate. Assume the cost of manipulating information is given by equation (40). Then, increasing the pay of politicians reduces the quality of politicians whenever,

$$
\left(\frac{\pi-w_{s}}{\pi-1}\right)^{2}<\frac{1-\bar{\sigma}}{\theta \bar{\sigma}}
$$

and improves it otherwise.

Proof. Given (44) we know that equilibrium quality of politicians, $q^{*}$, is decreasing in $\pi$ if the information manipulation effect is larger, in absolute value, then the information manipulation effect. That is

$$
\frac{\partial q^{*}}{\partial \pi}<0 \Leftrightarrow-\frac{\partial \sigma^{*}}{\partial \pi} \frac{1}{\sigma^{*}}>\frac{1-\sigma^{*}}{\pi-w_{s}}
$$

Using (46) and (41) we can substitute for the explicit value of $\frac{\partial \sigma^{*}}{\partial \pi} \frac{1}{\sigma^{*}}$ and $\sigma^{*}$ to obtain

$$
\frac{\partial q^{*}}{\partial \pi}<0 \Leftrightarrow-\frac{\bar{\sigma} \theta}{\theta \bar{\sigma}-\hat{\sigma}} \frac{\partial \hat{\sigma}}{\partial \pi} \frac{1}{\hat{\sigma}}>\frac{\theta \bar{\sigma}-\hat{\sigma}(1+\bar{\sigma}(\theta-1))}{\theta \bar{\sigma}-\hat{\sigma}} \frac{1}{\pi-w_{s}}
$$

Substituting for for $\frac{\partial \hat{\sigma}}{\partial \pi} \frac{1}{\hat{\sigma}}$ and $\hat{\sigma}$, using (26) and (25), we get

$$
\frac{\partial q^{*}}{\partial \pi}<0 \Leftrightarrow \bar{\sigma} \theta\left(\frac{w_{s}-1}{\pi-1}\right)>\theta \bar{\sigma}-\frac{(\pi-1)}{\left(\pi-w_{s}\right)}(1-\bar{\sigma})
$$


Collecting, $\bar{\sigma} \theta$, multiplying both sides by $\pi-1$ and $\pi-w_{s}$, and dividing both sides by $\theta \bar{\sigma}$ yields condition (47),

$$
\frac{\partial q^{*}}{\partial \pi}<0 \Leftrightarrow\left(\frac{\pi-w_{s}}{\pi-1}\right)^{2}<\frac{1-\bar{\sigma}}{\bar{\sigma} \theta}
$$

Quite intuitively, according to Proposition 1, with the specific cost function (40), an increase in the pay of politicians' reduces the quality of politicians whenever, other things equal,

i. $\theta$ is relatively small. If parties' technology for information manipulation is efficient so that manipulation is cost-effective, i.e. in captured societies where parties control the process of production of information about candidates, the manipulation effect is comparatively stronger;

ii. $\bar{\sigma}$ is relatively small. The less informative is the public signal that citizen receive in the absence of information manipulation, i.e. the less aware a society is, then the information manipulation effect is larger, and the selection effect is comparatively smaller.

iii. $\frac{\pi-w_{s}}{\pi-1}$ is relatively small. When politicians reward is small compared to the market wage of skilled citizens, the latter have less incentive to run for politics and the selection effect is comparatively smaller.

Notice that cases (i) and (ii) might well be self-reinforcing. In other words, $\theta$ and $\bar{\sigma}$ might be positively correlated. On the one hand, it looks more likely that manipulating information is cheaper in less aware societies, where the quality of media and the average level of citizens' concern and ability to process information correctly is low. On the other hand, in captured societies manipulating information is cheap and we expect that parties take advantage of this by choosing a higher degree of information manipulation ( $\sigma^{*}$ is low when $\theta$ is low, see equation $(41)$ ). One then may expect that exposing citizens to a high degree of information manipulation for a significant amount of time can affect their "exogenous" level of concern and their ability to process informations correctly. We leave the analysis of such interaction for future research, and we simply observe that the alleged positive correlation between $\bar{\sigma}$ and $\theta$ would strengthen our argument.

\subsection{Empirical implications}

What are the empirical implications of our model? To what extent our results provide a rationale for the relationship between rewards for public office and quality of politicians in Italy and in USA described in the introduction? Let us assume that the left the left-hand side of condition (47) is similar in US and Italy. ${ }^{19}$ Then, our model predicts that if quality of politicians and politicians' pay are negatively correlated in the case of Italy, and positive correlated in the case of the US, we

\footnotetext{
${ }^{19}$ Using OECD data (OECD, 2011) for earnings premiums from tertiary education, Barro-Lee dataset (Barro and Lee, 2010) for the percentage of population with a tertiary degree, Piketty (2014) estimates on labour share and public informations for politicians pay in US and Italy, we have calibrated the LHS of $(47)$, $\left(\frac{\pi-w_{s}}{\pi-1}\right)^{2}$, for the US and Italy from 1999 to 2009. The estimates for the two countries turn out to be very close. In US the estimated value of the LHS of condition (47) ranges from 0.74 to 0.77 while in Italy it ranges from 0.79 to 0.89 .
} 
should expect the extent to which the society is captured - i.e. the ability of parties to manipulate information about candidates, by controlling the institutions involved with the production of such information, which is measured by $\theta$ in the model - and/or the level of citizen awareness, measured by $\bar{\sigma}$ in the model, to be lower in Italy than in the US. As already mentioned in the introduction, despite finding proper proxies for these quantities is not an easy task, we propose two indexes of press freedom as a proxy for parties' ability to manipulate information $(\theta)$ and the so-called Index of Ignorance elaborated by IPSOS-MORI as a proxy for citizens' awareness $(\bar{\sigma})$. As shown in figure 4 , according to the Press Freedom Index elaborated by Reporters Without Borders, since 2002, Italy's ranking ranges between 35th (out of 164 in 2007) and 73rd (out of 180 in 2015), while the US's ranking ranges between 17th (out of 134 in 2002) and 53rd (out of 161 in 2006). An even sharper picture emerges from the Freedom of the Press index elaborated by Freedom House according to which, among 186 countries and since 2002, Italy rank ranges from a maximum of 52nd (in 2002) to a minimum of 79th (out of 194 in 2006) while US rank ranges from a maximum of 15 th (out of 193 in 2004) to a minimum of 31st (in 2015 out of 199) as shown in figure 5. Moreover, Freedom House defines Italian press as "partly free" in 10 of the last 14 years while US press is always defined "free". Indeed, these observations suggest that manipulating information is more difficult in the US than in Italy which, in our model, translates in a lower value of $\theta$ in Italy than in the US. As for the Ignorance index, Italy is the most ignorant country among the 14 considered, suggesting that citizens' awareness (and then the level of $\bar{\sigma}$ ) is lower in Italy than in the US. These empirical findings seem to support the model's predictions and suggest that the mechanism we propose might have a role in explaining the observed data.

Finally, for the subsample of 14 countries for which the information on both the above mentioned freedom of press and the ignorance indexes is available, we have computed the correlation between country's relative average rankings during 2002-2015 in the ignorance and freedom of press crosscountry tables (see also figures 6 , and 7 ). Such correlation is equal to -0.57 is we consider the Freedom of the Press index by Freedom House and to and -0.61 if we consider Press Freedom index elaborated by Reporters Without Borders. Such correlation between these two variable is consistent with our priors about the fact that the fact that a captured society should also be less aware.

\section{Conclusions}

We analyze how such relationship could be affected when parties play a role in the selection of politicians, and show that the relationship between quality and pay of politicians is ambiguous. We show the existence of an equilibrium where increasing politicians' pay reduces the average quality of politicians. Such equilibrium is more likely to exist when (i) parties are sufficiently effective at manipulating information, i.e. in captured societies in which parties effectively control the institutions involved at society level with the production of information about candidates, and/or (ii) the society is less aware, i.e. the quality of information available about perspective politicians is relatively low, due for instance to the bad quality of the media or because citizens have little concern about politics. In such contexts, political parties may prefer to bear the additional cost of distorting information 


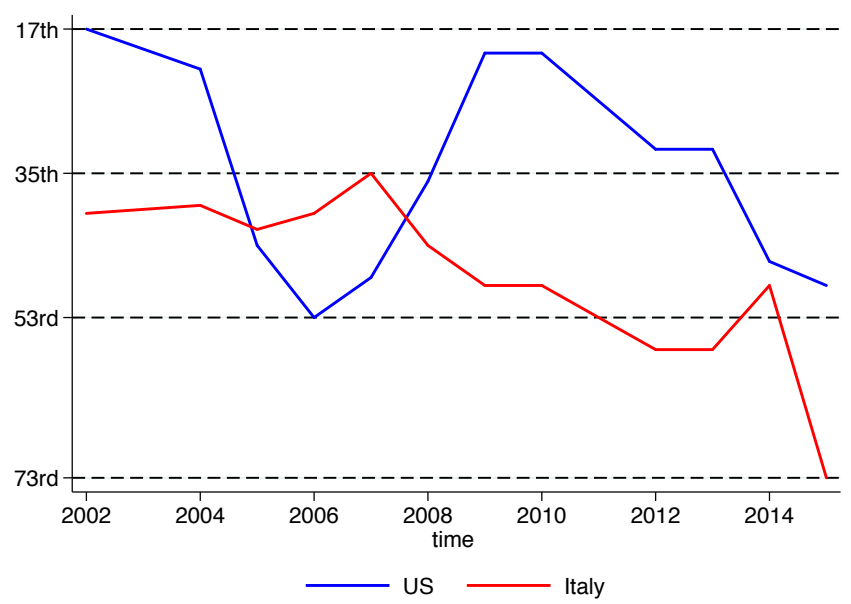

Figure 4: Trends of Italy's and US's ranking positions according to the Press Freedom index by Reporters Without Borders, 2002-15.

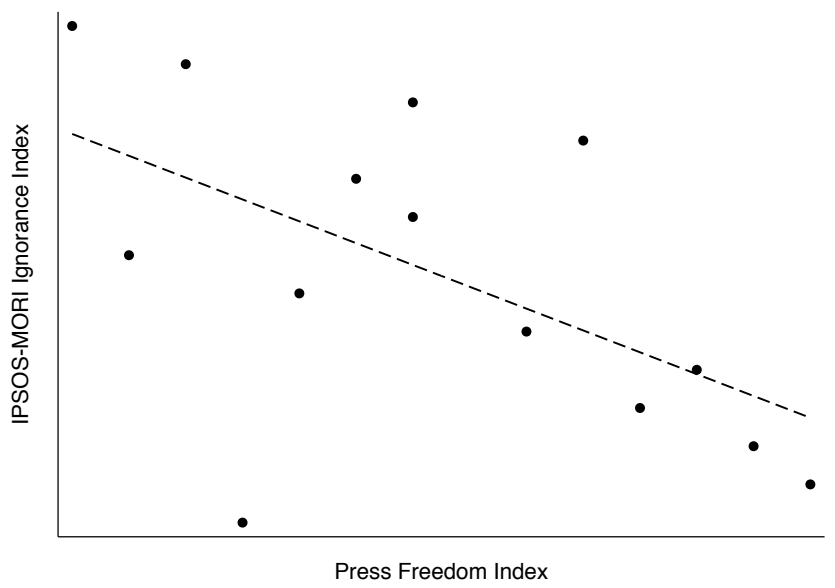

Figure 6: Cross-country linear relationship between IPSOS-MORI index and Press Freedom Index rankings. For the Press Freedom Index we consider the time-series average ranking over the available periods.

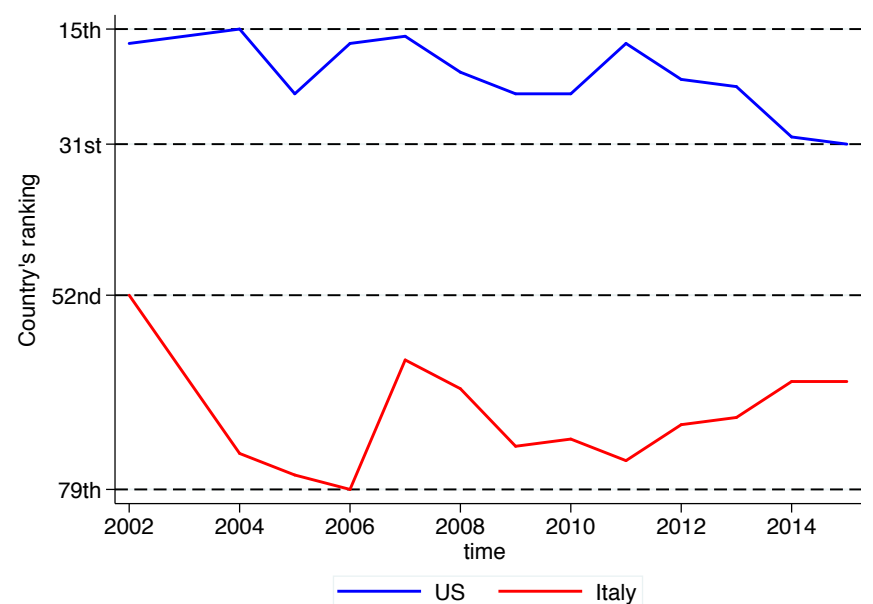

Figure 5: Trends of Italy's and US's ranking positions according to the Freedom of Press Index by Freedom House, 2002-15.

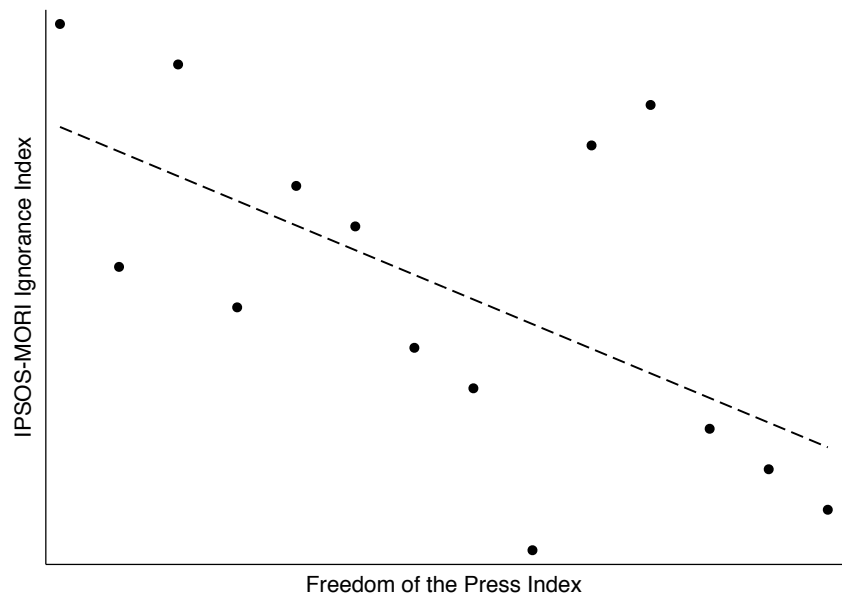

Figure 7: Cross-country linear relationship between IPSOS-MORI index and Freedom of the Press Index rankings. For the Freedom of Press Index we consider the timeseries average ranking over the available periods.

through aggressive political campaign in order to increase the probability of elections for unskilled candidates whom, in case of election, would be willing to provide higher party duties relative to skilled politicians. The empirical literature on how remuneration of politicians affects their quality delivers convincing evidence that the sign of the relationship could be positive only at local level. At national level, the evidence is far more mixed, providing the case for an ambiguous relationship. This is consistent with our theoretical results, to the extent that the informational disadvantage of citizen as far as the quality of candidates is concerned, might be higher in the case of national elections than in that of local ones. 


\section{References}

[1] Barro, R. and Lee, J., 2010. "A New Data Set of Educational Attainment in the World, 1950-2010." Journal of Development Economics, 104: 184-198.

[2] Besley T., 2004. "Paying Politicians: Theory and Evidence". Journal of the European Economic Association, 2: 193-215.

[3] Besley T., 2005. "Political Selection". Journal of Economic Perspectives, 19: 43-60.

[4] Besley T., Folke O., Persson T., and Rickne J., 2014, "Gender Quotas and the Crisis of the Mediocre Man: Theory and Evidence from Sweden", mimeo.

[5] Besley, T., Montalvo J. G., and Reynal-Querol M., 2011. "Educated leaders matter". The Economic Journal, 554: 205-227.

[6] Besley, T., Pande R., and Rao V., 2005. "Political selection and the quality of government: Evidence from South India". Economic Growth Center, Yale Un. DP N. 921.

[7] Besley, T and Prat A., 2006, "Handcuffs for the grabbing hand? Media capture and government accountability". American Economic Review, 96: 720-736.

[8] Bernheim B.D, and Kartik N., 2014. "Candidates, Character, and Corruption". American Economic Journal: Microeconomics, 6: 205-246.

[9] Braendle, T. 2015. "Does remuneration affect the discipline and the selection of politicians? Evidence from pay harmonization in the European Parliament". Public Choice,162: 1-24.

[10] Calliaud B and Tirole J., 2002, "Parties as Political Intermediaries". Quarterly Journal of Economics, 117: 1453-1489.

[11] Carrillo J.D. and Mariotti T., 2001, "Electoral competition and politician turnover". European Economic Review, 45: 1-25.

[12] Caselli F. and Morelli M., 2004. "Bad Politicians". Journal of Public Economics, 88: 759-782.

[13] Caselli F. and Morelli M., 2001. "Bad Politicians". NBER Working Paper 8532

[14] Dal bo E., Finan F. and Rossi M, 2013. "Strengthening State Capabilities: The Role of Financial Incentives in the Call to Public Service". Quarterly Journal of Economics, 128: 1169-1218.

[15] Djankov, S., McLiesh C, Nenova T. and Shleifer, A., 2003. "Who Owns the Media?". Journal of Law and Economics, 46: 341-81.

[16] Ferraz C. and Finan F., 2009. "Motivating Politicians". NBER Working Paper 14906.

[17] Fisman R., Harmon N., Kamenica E. and Munk I., 2015. "Labor Supply of Politicians". Journal of European Economic Association, Forthcoming. 
[18] Gagliarducci S. and Nannicini T., 2013. "Do better paid politicians perform better? Disentangling Incentives from Selection". Journal of the European Economic Association, 11: 369-398.

[19] Galeotti A and Mattozzi A., 2011, "'Personal Influence': Social Context and Political Competition", American Economic Journal: Microeconomics

[20] Hoffman M. and Lyons E., 2013. "Do Higher Salaries Lead to Higher Performance? Evidence from State Politicians". Mimeo.

[21] Keane, M. P. and Merlo A., 2010. "Money, Political Ambition, and the Career Decisions of Politicians". American Economic Journal: Microeconomics, 2: 186-215.

[22] Kotakorpi, K., and Poutvaara P., 2011. "Pay for Politicians and Candidate Selection: An Empirical Analysis". Journal of Public Economics, 95: 877-885.

[23] Mattozzi A. and Merlo A., 2008. "Political careers or career politicians?". Journal of Public Economics, 92: 597-608.

[24] Mattozzi A. and Merlo A., 2015. "Mediocracy". Journal of Public Economics, 130: 32-44.

[25] Merlo A., Galasso V., Landi M. and Mattozzi A., 2008, "The Labor Market of Italian Politicians". Carlo Alberto Notebooks 89, Collegio Carlo Alberto.

[26] Messner M. and Polborn M., 2004. "Paying Politicians". Journal of Public Economics, 88: 24232445.

[27] Piketty T. and Zucman G., 2014, "Capital is back: Wealth-Income Rations in Rich Countries 1700-2010", Quarterly Journal of Economics, 124: 1255-1310.

[28] Poutvaara P. and Takalo T., 2007, "Candidate Quality", International Tax and Public Finance, 14: $7-27$.

[29] Snyder J.M. and M.M. Ting, 2002, "An Informational Rationale for Political Parties". American Journal of Political Science 46: 90-110. 